\title{
Rancangan Aplikasi Pelayanan Kesehatan Berbasis Geographic Information System (GIS) Versi Android di Kota Pekanbaru
}

\author{
Triyani Arita Fitri ${ }^{1 *}$, M. Naofal Arsyad ${ }^{2}$ \\ ${ }^{I}$ STMIK Amik Riau \\ ${ }^{2}$ STMIK Amik Riau \\ triyani@stmik-amik-riau.ac.id
}

\begin{abstract}
In line with the advancement of the times, services in the health sector are required to improve the quality. Particularly in Pekanbaru city there needs to be synergy among various units such as hospitals, Puskesmas, clinics, clinics, and pharmacies. Service users do not know clearly the locations of medical services in the region. Includes the quality of each. This is due to the vastness of urban areas and the lack of access to information. One option in achieving this target is to use the support of information and communication technology (ICT). This paper aims to describe the mechanism of software development based on GIS (Geographical Information System) that can be accessed on the android system to obtain information medical services. Achievement of this is done by performing initial identification, analysis and system design, execution activities. The initial identification is to classify the types of medical services and their geographical position. Furthermore, this activity continued by analyzing the needs of the system followed by creating the application model design. The next stage is to apply the design result to the software. The existence of this application system is expected to facilitate Pekanbaru residents in obtaining various information related to medical service location, the shortest path (route) to achieve it, and the quality (medical personnel, facilities, and comfort). In addition, applications can be downloaded for free by the public.
\end{abstract}

Keywords: GIS, Medical Service, Android

\begin{abstract}
Abstrak
Sejalan dengan kemajuan zaman, layanan di sektor kesehatan diharuskan untuk meningkatkan kualitas. Khususnya di kota Pekanbaru perlu ada sinergi antar berbagai unit seperti rumah sakit, puskesmas, klinik, klinik, dan apotek. Pengguna layanan tidak mengetahui secara jelas lokasi layanan medis di wilayah tersebut. Termasuk kualitas masing-masing. Hal ini disebabkan luasnya daerah perkotaan dan kurangnya akses terhadap informasi. Salah satu pilihan dalam mencapai target ini adalah dengan menggunakan dukungan teknologi informasi dan komunikasi (TIK). Makalah ini bertujuan untuk menggambarkan mekanisme pengembangan perangkat lunak berbasis GIS (Sistem Informasi Geografis) yang dapat diakses pada sistem android untuk memperoleh informasi pelayanan medis. Pencapaian ini dilakukan dengan melakukan identifikasi awal, analisis dan perancangan sistem, pelaksanaan kegiatan. Identifikasi awal adalah untuk mengklasifikasikan jenis layanan medis dan posisi geografis mereka. Selanjutnya, kegiatan ini dilanjutkan dengan menganalisa kebutuhan sistem diikuti dengan pembuatan desain model aplikasi. Tahap selanjutnya adalah menerapkan hasil perancangan ke perangkat lunak. Keberadaan sistem aplikasi ini diharapkan dapat mempermudah warga Pekanbaru dalam mendapatkan berbagai informasi yang berkaitan dengan lokasi pelayanan medis, jalur terpendek (jalur) untuk mencapainya, dan kualitas (tenaga medis, fasilitas, dan kenyamanan). Selain itu, aplikasi bisa diunduh secara gratis oleh publik.
\end{abstract}

Kata kunci: GIS, Layanan Medis, Android 


\section{Pendahuluan}

Teknologi telah memberikan kemudahan bagi kita dalam kehidupan ini, hampir setiap aspek kehidupan sudah memanfaatkan kecanggihan teknologi.Beberapa fasilitas teknologi dimanfaatkan untuk mempermudah komunikasi atau untuk mendapatkan informasi. Dengan kemajuan teknologi yang semakin pesat pada saat ini berpengaruh pada perkembangan teknologi mobile pada perangkat telepon pintar (smartphone) dengan sistem operasi Android. Dengan semakin bertambahnya kebutuhan akan fitur-fitur baru pada smartphone membuat para vendor mengembangkan teknologi-teknologi baru untuk setiap produk mereka. Salah satu teknologi yang diaplikasikan di perangkat smartphone saat ini adalah teknologi Global Positioning System (GPS).Dengan memanfaatkan GPS,pengguna dapat mengetahui posisi keberadaannya secara real time.

Geographic Information System(GIS) dengan menggunakan metode Location-Based Service (LBS) yang memanfaatkan teknologi GPS dalam pengaplikasiannya.Selain dapat mengetahui posisi pengguna, metode ini dapat menampilkan dan menentukan posisi tempat tertentu, dengan kombinasi ini suatu aplikasi yang di rancang akan menampilkan pemetaan suatu lokasi dan dapat mencari rute untuk menghubungkan posisi pengguna dengan suatu tempat.

Pekanbaru merupakan ibukota dari provinsi Riau, sebagai ibukota provinsi, tentunya Pekanbaru menjadi sebuah kota yang dihuni oleh banyak jiwa dan dituju masyarakat dari berbagai penjuru di Riau. Sebagai kota yang memiliki tingkat pertumbuhan penduduk yang tinggi dan perkembangan kota yang pesat, Pekanbarusudah memiliki fasilitas dan pelayanan kesehatan yang sangat lengkap seperti rumah sakit, balai pengobatan, apotik, klinik dan puskesmas.

Informasi pelayanan kesehatan terdekat berguna bagi masyarakat terutama dalam keadaan darurat seperti kecelakaan kerja, kecelakaan lalu lintas dan lain-lain. Rumah sakit atau klinik terdekat merupakan tempat yang dituju oleh setiap orang ketika memerlukan pelayanan medis dengan segera. Informasi lokasi, jarak serta fasilitas yang diberikan akan menjadi pertimbangan masyarakat untuk memilih sebuah tempat pelayanan kesehatan yang dianggap tepat. Solusi yang diberikan adalah tersedianya informasi lokasi layanan kesehatan berbasis mobile menggunakan sistem operasi Android. Sistem ini dapat memudahkan pengguna untuk melakukan pencarian lokasi serta fasilitas yang diberikan penyedia layanan kesehatan terdekat. Tujuan yang ingin dicapai dari penelitian ini adalah merancang aplikasi pelayanan kesehatan dengan menggunakan Geographic Information System(GIS) untuk mendapatkan informasi lokasi pelayanan kesehatan yaitu rumah sakit, puskesmas, klinik dan apotik serta lokasi suatu daerah yang disajikan dalam peta digital.

Hasil penelitian ini diharapkan dapat memberikan kemudahan kepada masyarakat dalam mencari lokasi atau tempat pelayanan kesehatan yang ada di kota Pekanbaru dalam bentuk peta digital dan dapat diakses oleh masyarakat melalui perangkat mobile Android.

Berdasarkan UU RI Tahun 1992 tentang kesehatan pasal 1 ayat 2 pengertian upaya atau pelayanan kesehatan adalah setiap kegiatan untuk memelihara atau meningkatkan kesehatan yang dilakukan oleh pemerintah atau masyarakat. Terdapat beberapa tempat pelayanan kesehatan yaitu rumah sakit, puskesmas , klinik dan apotik .

Geographic Information System (GIS) atau dalam bahasa Indonesia biasa dikenal dengan Sistem Informasi Geografis (SIG) merupakansistem infomasi berbasis komputer yang merupakan penggabungan antara unsur peta (geografis) daninformasi tentang peta tersebut (data atribut), yangdirancang untuk mendapatkan, mengolah, memanipulasi,analisis, memperagakan dan menampilkandata spasial untuk menyelesaikan perencanaan,mengolah dan meneliti permasalahan. SIG padadasarnya merupakan 
gabungan dari tiga unsur pokokyaitu: sistem, informasi dan geografis. [3]

Google Map Service adalah sebuah jasa peta global virtual gratis dan online yang disediakan oleh perusahaan Google.Google Maps yang dapat ditemukan di alamat http://maps.google.com GoogleMaps menawarkan peta yang dapat diseret dan gambar satelit untuk seluruh dunia, dan juga menawarkan pencarian suatu tempat dan rute perjalanan. [2]

GPS merupakan sistem radio navigasi dan penentuan posisi dengan menggunakan satelit navigasi yang dimiliki dan dikelola oleh departemen pertahanan Amerika Serikat.[4]

Location Based Service adalah istilah umum yang digunakan untuk menggambarkan teknologi yang digunakan untuk menemukan lokasi perangkat lunak yang kita gunakan.[5] Dua unsur utama LBS adalah :

1. Location Manager (API Maps)

2. LocationProviders (API Location)

Android merupakan sistem operasi mobile yang berbasiskan pada versi modifikasi dari Linux . Sistem ini dikembangkan pertama kalinya oleh perusahaan android.inc yang akhirnya menjadikan nama perusahaan tersebut sebagai nama dari sistem operasi mobile yang dikembangkannya yaitu sistem operasi android. [6]

\section{Metoda Penelitian}

\subsection{Sumber Data}

Sumber data dalam penelitian ini diperoleh melalui sumber yang terkait untuk mendapatkan titik lokasi layanan kesehatan yang di ambil langsung ke lokasi layanan kesehatan mulai dari titik koordinat, dekripsi layanan kesehatan yang tersedia, dan gambar tempat layanan kesehatan tersebut.

\subsection{Tahapan Pengembangan Perangkat Lunak}

Tahapan SDLC yang digunakan didalam penelitian ini terdiri dari :

\section{Analisis Sistem}

Pada tahap ini data dan informasi layanan kesehatan yang telah diperoleh akan didokumentasikan kemudian diolah sebagai bahan awal untuk mendapatkan proses input dan output, pada tahap ini yang diproses adalah segala informasi mengenai lokasi, dekripsi, layanan yang ada terhadap rumahsakit, klinik, puskesmas, dan apotek yang diteliti.

\section{Perancangan Sistem}

Perancangan sistem di lakukan dengan menggunakan Unified Modelling Language (UML) untuk memperjelas apa saja yang dapat di akses oleh pengguna, apa saja yang dapat di akses oleh administrator. Dokumen yang dipersiapkan pada tahap ini adalah Process Modeling, Data Modeling, dan Interface Modeling.

3. Implementasi dan Pengkodean

Dalam pengkodean program digunakan Eclipsesebagaiaplikasibahasapemogramanmob ile yang digunakan untuk menghasilkan sebuah aplikasi Android. Agar dapat menampilkan peta setiap lokasi digunakanlah tool dari Google Maps yaitu Google Maps Api agar dapat menampilkan titik lokasi dari suatu tempat dan memanfaatkan metode LBS untuk dapat mencari jalur rute dari posisi kita berada ke posisi tujuan. Untuk databasenya sendiri menggunakan MySQL dan dibuat Web Administrator, sehingga jika terjadi pembaharuan terhadap segalainput pelayanan kesehatan, baik itu lokasi, dekripsi dan lainnya dapat dilakukan secara dinamis tanpa merubah isi sintaks pengkodean didalam aplikasi Eclipse yang dirancang.

4. Pengujian dan Implementasi

Pada tahap ini ketika penggunaan aplikasi, GPS haruslah aktif agar dapat menampilkan pemetaan yang telah di buat. Tahap pengujian program dilakukan untuk mendeteksi kesalahan yang terdapat saat proses pengkodean sampai menghasilkan aplikasi yang sesuai dengan rancangan. Setelah sistem dinyatakan berhasil , maka dilanjutkan pada tahap implementasi pada user yang menangani aplikasi ini. 


\section{Hasil Penelitian}

\subsection{Analisa Sistem yang Diusulkan}

Aplikasi yang diusulkan dapat memudahkan pengguna untuk melakukan pencarian lokasi serta fasilitas yang diberikan penyedia layanan kesehatan terdekat dengan menggunakan perangkat mobile. Pada aplikasi ini dibutuhkan sample data dari lokasi pelayanan kesehatan dan informasi lainnya sebagai akses yang mudah bagi masyarakat untuk mendapatkan keakuratan informasi.Sampel dari data lokasi pelayanan kesehatan yang telah ditentukan koordinatnya dengan menggunakan service dari Google berupa Google Maps, dan kategori dari pelayanan kesehatan dibagi atas 4 jenis yaitu apotek, klinik, puskesmas dan rumah sakit.

\subsection{Perancangan Use Case Diagram}

Use Case Diagram merupakan permodelan untuk menggambarkan kelakuan (behavior) sistem yang akan dibuat. Diagram usecase mendeskripsikan sebuah interaksi antara satu atau lebih aktor dengan sistem yang dibuat. [7]

Use Case Diagram dari sistem pencarian lokasi pelayanan kesehatan di Kota Pekanbaruadalah gambaran keseluruhan terhadap sistem yang akan dikembangkan seperti yang terlihat pada gambar 1 dibawah ini.

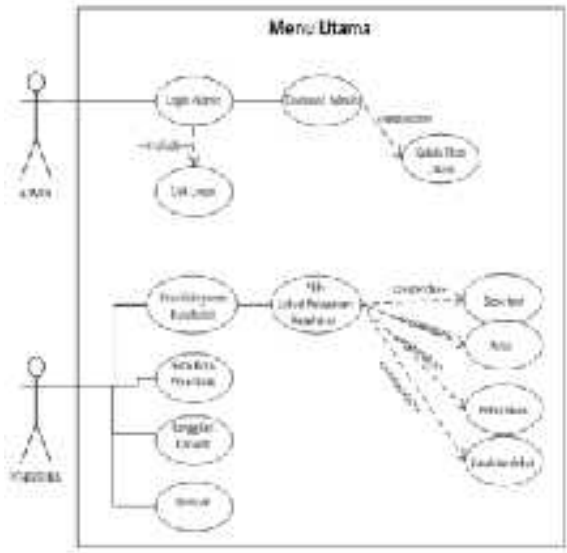

Gambar 1. Use Case Diagram

Use Case Diagram dari penerapan Geographic Information System (GIS) dan Location Based Service (LBS) pada pencarianlokasi pelayanan kesehatan di Kota Pekanbaru dengan menggunakan perangkat android yang diperlihatkan pada gambar 1 diatas dapat dijelaskan sebagai berikut :

1. Pengguna adalah yang akan menggunakan sistem.

2. Menu utama adalah tampilan awal saat aplikasi dijalankan.

3. Pada menu pilih pelayanan kesehatan, pengguna dapat memilih ingin mencari apotek, klinik, puskesmas atau rumah sakit.

4. Setelah menu pelayanan kesehatan dipilih, pengguna dapat memilih lokasi yang terdekat berdasarkan jarak yang ditampilkan.

5. Foto, dekripsi, jarak akan ditampilkan setelah pengguna memilih pelayanan kesehatan.

6. Pengguna dapat mengarahkan lokasi dari tempat berada ke tempat tujuan dengan klik pilihan peta pada tampilan pelayanan kesehatan yang terbuka.

7. Pengguna dapat menampilkan peta kota Pekanbaru beserta seluruh lokasi pelayanan kesehatan yang ada didatabase

8. Pengguna dapat menghubungi nomor darurat secara pintas di aplikasi.

9. Pada bagian admin, admin dapat melakukan proses login dan diverifikasi terlebih dahulu.

10. Setelah admin login, admin dapat mengelola seluruh data dari pelayanan kesehatan.

\subsection{Perancangan Activity Diagram}

Activity Diagram merupakan diagram yang memodelkan workflow proses bisnis dan urutan aktivitas dalam sebuah proses.[8] Activity diagram yang dirancang pada sistem pencarian lokasi pelayanan kesehatan di kota Pekanbaru adalah sebagai berikut :

1. Activity diagram pilihan menu pelayanan kesehatan.

Berikut ini merupakan Activity Diagram dari proses menu pilihan pelayanan kesehatan. Pengguna akan masuk ke menu utama lalu memilih menu pilih pelayanan kesehatan dimana pada menu ini akan ditampilkan 
kategori dari pelayanan kesehatan yang ada seperti apotek, klinik, puskesmas dan rumah sakit.

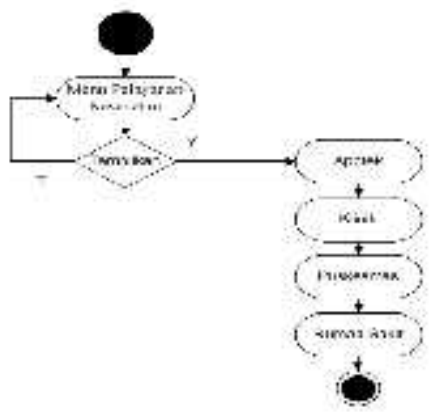

Gambar 2. Activity diagram pilihan menu pelayanan kesehatan

2. Activity diagram pilihan lokasi pelayanan kesehatan.

Pada gambar 3 merupakan activity diagram dari proses pemilihan lokasi pelayanan kesehatan. Pada proses ini pengguna dapat melihat foto, dekripsi, jarak dan peta pelayanan kesehatan yang telah dipilih.

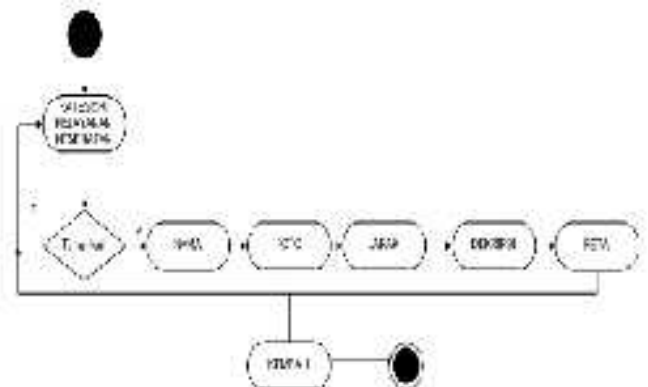

Gambar 3. Activity diagram pilihan lokasi pelayanan kesehatan

3. Activity diagram mengarahkan lokasi awal ke tujuan.

Pada activity diagram ini pengguna dapat melakukan penentuan rute secara otomatis. Aplikasi dapat menentukan jarak terpendek yang dapat di tempuh seperti gambar 4 berikut.

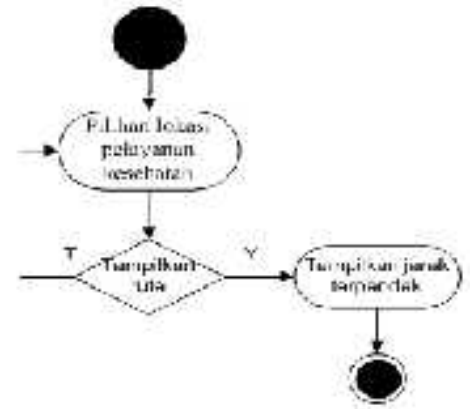

Gambar 4. Activity diagram mengarahkan lokasi awal ke tujuan

4. Activity diagram kelola data pelayanan kesehatan.

Pada activity diagram ini dapat dijelaskan proses pengolahan data lokasi pelayanan kesehatan, dimana proses ini akan dilakukan oleh admin yang memulai dengan masuk ke menu admin melalui web administrator, selanjutnya melakukan login untuk dapat masuk ke dashboard admin agar dapat melakukan pengolahan lokasi dan lainnya, berikut alur aktifitasnya.

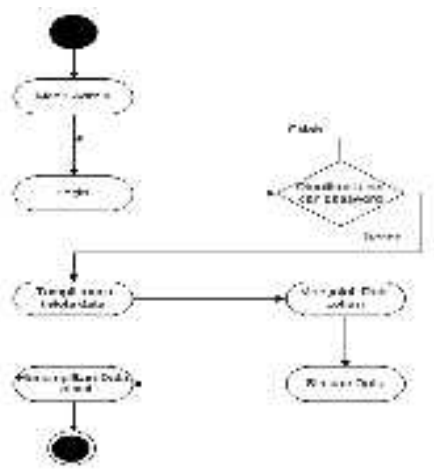

Gambar 5. Activity diagram kelola data pelayanan kesehatan

5. Activity diagram menampilkan peta kota Pekanbaru

Pada rancangan activity diagramdari menu peta kota Pekanbaru, pengguna dapat menampilkan peta dan seluruh koordinat lokasi pelayanan kesehatan di kota Pekanbaru. 


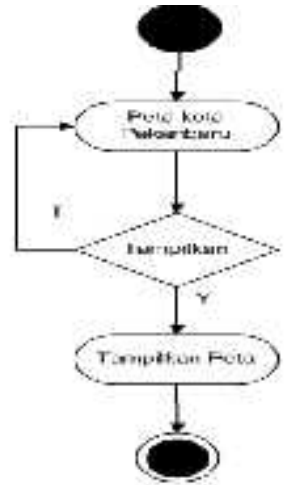

Gambar 6. Activity diagram menampilkan peta kota Pekanbaru sedangkan tabel admin digunakan untuk mengelola data lokasi layanan kesehatan.

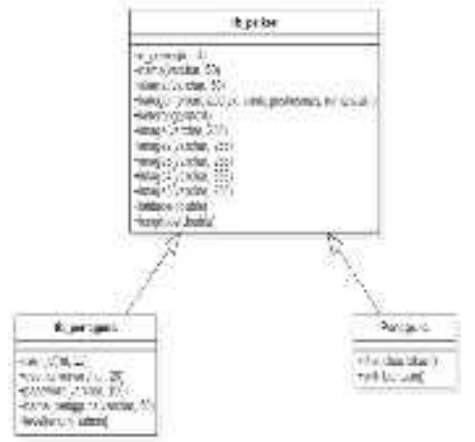

Gambar 8. Class Diagram

\subsection{Hasil Implementasi Sistem}

1. Halaman Splash Screen Halaman ini aktif dan muncul ketika pengguna pertama kali menjalankan aplikasi yang berfungsi menampilkan proses load aplikasi.

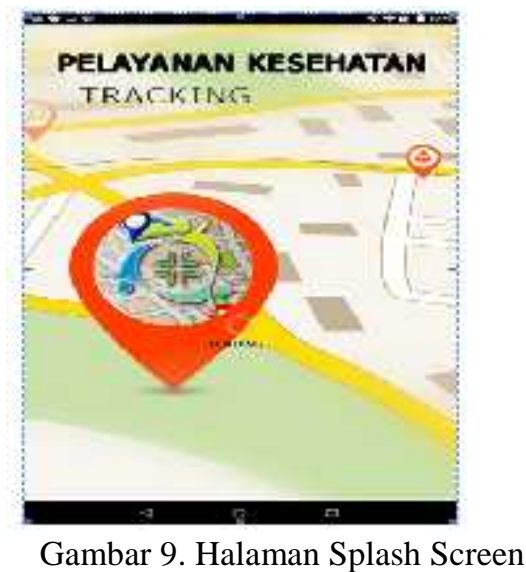

2. Halaman Menu Utama

Halaman ini akan aktif pertama kali setelah proses load pada tampilan splash screen selesai. Kemudian akan menampilkan daftardaftar kategori dari pelayanan kesehatan, yaitu apotek, klinik, puskesmas dan rumah sakit. Berikut tampilannya : 


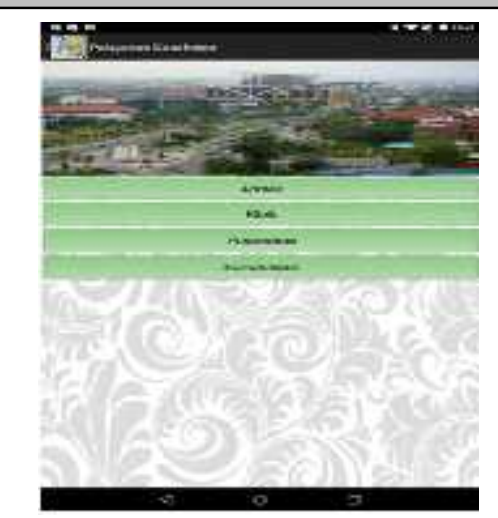

Gambar 10. Halaman Menu Utama

3. Halaman Pilihan Menu

Tampilan ini dapat diaktifkan dengan menggeser layar dari arah kiri ke kanan atau biasa di sebut sliding menu, didalam sub menu ini terdapat beberapa kategori yaitu, pelayanan kesehatan, fasilitas lain, peta kota Pekanbaru, panggilan darurat dan bantuan. Berikut tampilan dari pilihan menu.

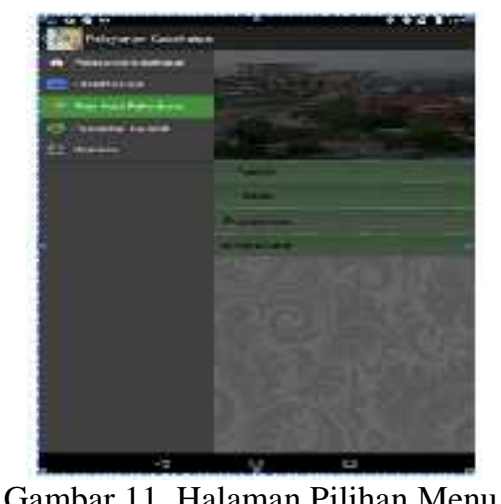

\section{Halaman Peta Kota Pekanbaru}

Halaman peta ini berfungsi untuk menampilkan peta kota Pekanbaru, beserta seluruh lokasi data koordinat pelayanan kesehatan yang terdapat didalam aplikasi, berikut tampilannya.

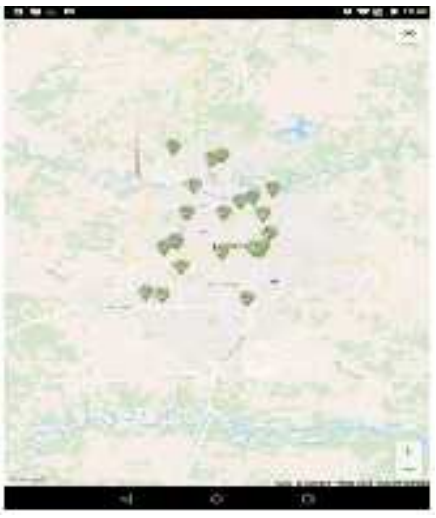

Gambar 12. Halaman Peta Kota Pekanbaru

5. Halaman Daftar Apotek

Halaman ini akan menampilkan seluruh data apotek yang terdapat didalam database aplikasi, tampilan sebagai berikut.

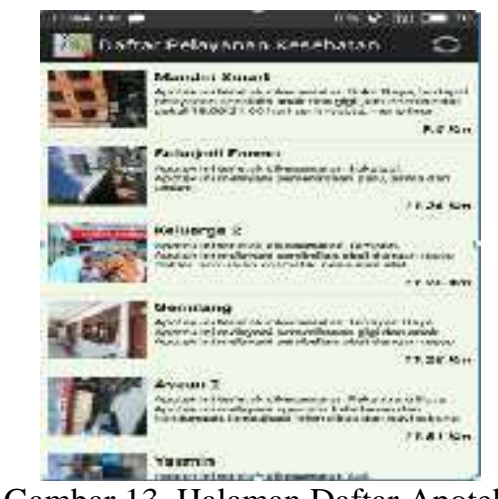

Gambar 13. Halaman Daftar Apotek

\section{Halaman Daftar Klinik}

Halaman ini akan menampilkan seluruh data klinik yang terdapat didalam database, tampilannya seperti berikut.

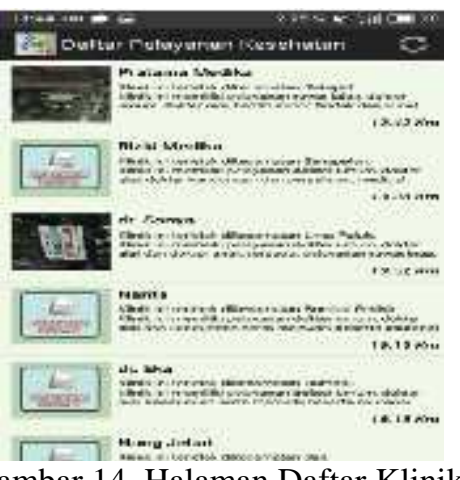

Gambar 14. Halaman Daftar Klinik 
7. Halaman Daftar Puskesmas

Halaman ini akan menampilkan seluruh data puskesmas yang terdapat didalam database, tampilannya seperti berikut.

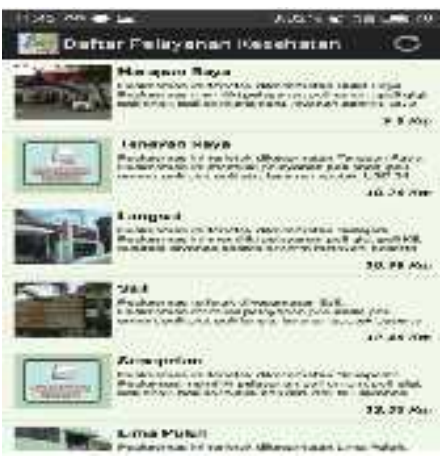

Gambar 15. Halaman Daftar Puskesmas

\section{Halaman Daftar Rumah Sakit}

Halaman ini akan menampilkan seluruh data rumah sakit yang terdapat didalam database, tampilannya seperti berikut.

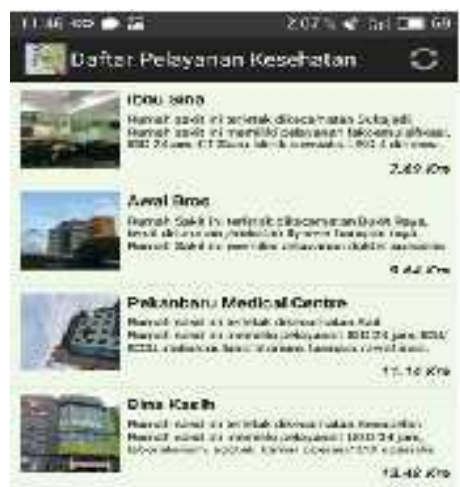

Gambar 16. Halaman Daftar Rumah Sakit

\subsection{Hasil Pengujian Sistem}

Hasil pengujian disini adalah melakukan pe-rutean terhadap aplikasi pelayanan kesehatan dari 3 (tiga) titik lokasi yang berbeda terhadap 1 (satu) tujuan lokasi yang sama.

1. Posisi pengguna pada mall SKA

Pengujian ini dilakukan saat posisi pengguna berada di kawasan mall SKA Jl.Soekarno Hatta dengan tujuan lokasi pelayanan kesehatan di PMC Jl.Lembaga Pemasyarakatan, seperti pada gambar 17 berikut.

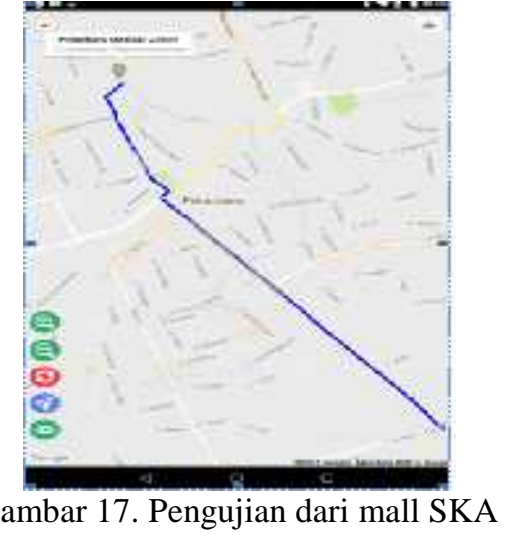

2. Posisi pengguna pada bandar udara Sultan Syarif Qasim

Pengujian ini dilakukan saat posisi pengguna berada di kawasan bandar udara Sultan Syarif Qasim dengan tujuan lokasi pelayanan kesehatan di PMC Jl.Lembaga Pemasyarakatan, seperti pada gambar 18 berikut.

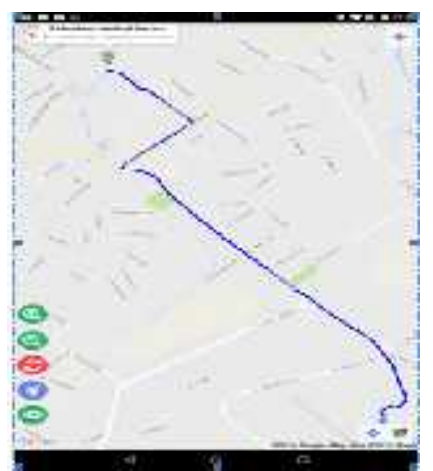

Gambar 18. Pengujian dari bandara udara Sultan Syarif Qasim

3. Posisi pengguna pada sudirman bawah Pengujian ini dilakukan saat posisi pengguna berada di kawasan sudriman bawah di Jl.Jend.Sudirman dengan tujuan lokasi pelayanan kesehatan di PMC Jl.Lembaga Pemasyarakatan, seperti pada gambar 19 berikut. 


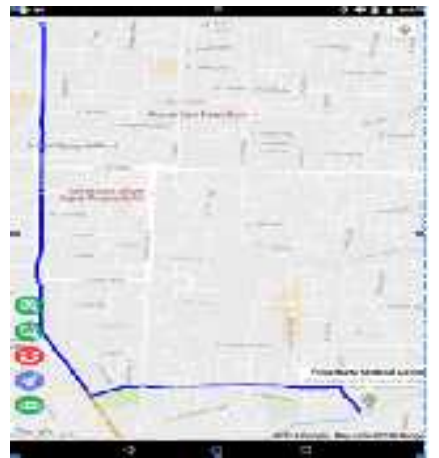

Gambar 19. Pengujian dari Jl.Jend.Sudirman

\subsection{Teknik Pengujian}

Pada hasil pengujian aplikasi disini digunakan metode Black Box dengan pengujian fungsi dasar sistem. Adapun hasil yang diperoleh dari pengujian fungsi dasar sistem dari aplikasi Pelayanan Kesehatan ini seperti pada tabel 1 dibawah ini :

Tabel 1..Pengujian fungsi dasar sistem

\begin{tabular}{|c|c|c|c|c|}
\hline No & $\begin{array}{c}\text { Kasus } \\
\text { Percobaan }\end{array}$ & $\begin{array}{l}\text { Hasil yang } \\
\text { diharapkan }\end{array}$ & $\begin{array}{c}\text { Hasil yang } \\
\text { terjadi }\end{array}$ & Hasil \\
\hline 1. & $\begin{array}{l}\text { Pengujian } \\
\text { fungsi } \\
\text { submenu }\end{array}$ & $\begin{array}{l}\text { Aplikasi akan } \\
\text { menampilkan } \\
\text { submenu atau } \\
\text { sliding menu } \\
\text { yang } \\
\text { diprogram } \\
\text { didalam } \\
\text { aplikasi }\end{array}$ & $\begin{array}{l}\text { Aplikasi } \\
\text { menampilkan } \\
\text { menu yang } \\
\text { ada sesuai } \\
\text { dengan } \\
\text { program yang } \\
\text { dirancang } \\
\text { pada aplikasi }\end{array}$ & Berhasil \\
\hline 2. & $\begin{array}{l}\text { Pengujian } \\
\text { daftar menu } \\
\text { pelayanan } \\
\text { kesehatan }\end{array}$ & $\begin{array}{l}\text { Aplikasi akan } \\
\text { menampilkan } \\
\text { daftar layanan } \\
\text { yang ada di } \\
\text { database, baik } \\
\text { itu apotek, } \\
\text { klinik, } \\
\text { puskesmas } \\
\text { atau rumah } \\
\text { sakit sesuai }\end{array}$ & $\begin{array}{l}\text { Aplikasi } \\
\text { menampilkan } \\
\text { daftar menu } \\
\text { pelayanan } \\
\text { kesehatan } \\
\text { sesuai dengan } \\
\text { kategori pada } \\
\text { database }\end{array}$ & Berhasil \\
\hline 3. & $\begin{array}{l}\text { Pengujian } \\
\text { menampilk } \\
\text { an peta kota } \\
\text { pekanbaru }\end{array}$ & $\begin{array}{l}\text { kategori } \\
\text { Aplikasi akan } \\
\text { menampilkan } \\
\text { peta kota } \\
\text { Pekanbaru } \\
\text { beserta } \\
\text { seluruh data } \\
\text { koordinat } \\
\text { pelayanan } \\
\text { kesehatan } \\
\text { yang ada di } \\
\text { kota } \\
\text { Pekanbaru }\end{array}$ & $\begin{array}{l}\text { Aplikasi } \\
\text { dapat } \\
\text { menampilkan } \\
\text { peta kota } \\
\text { Pekanbaru } \\
\text { dan } \\
\text { menampilkan } \\
\text { titik koordinat } \\
\text { semua data } \\
\text { yang ada } \\
\text { didatabase }\end{array}$ & Berhasil \\
\hline 4. & $\begin{array}{l}\text { Pengujian } \\
\text { menampilk } \\
\text { an jarak } \\
\text { rute dari } \\
\text { pengguna } \\
\text { ke tujuan }\end{array}$ & $\begin{array}{l}\text { Aplikasi } \\
\text { menampilkan } \\
\text { rute } \\
\text { terpendek } \\
\text { yang dapat } \\
\text { ditempuh } \\
\text { oleh } \\
\text { pengguna } \\
\text { untuk menuju } \\
\text { tujuan }\end{array}$ & $\begin{array}{l}\text { Aplikasi } \\
\text { menampilkan } \\
\text { rute dengan } \\
\text { menunjukkan } \\
\text { nya melalui } \\
\text { garis lalu } \\
\text { yang dapat } \\
\text { diikuti oleh } \\
\text { pengguna } \\
\text { untuk menuju }\end{array}$ & Berhasil \\
\hline
\end{tabular}

tujuan yang

dipilih

Aplikasimena mpilkanseluru

$\mathrm{h}$ data detail

yang

Berhasil

ngsi detail

pilihan

database

luruh data

sesuai yang

adadidalam

database

adadidalam

database

\section{Kesimpulan}

Kesimpulan dari penelitian ini adalah :

1. Aplikasi ini memberikan informasi kepada masyarakat kota Pekanbaru terhadap pelayanan kesehatan yang ada di kota Pekanbaru baik itu apotek, klinik, puskesmas dan rumah sakit.

2. Informasi dan data yang akan ditampilkan menjadi lebih memudahkan pengguna menentukan lokasi yang dituju sesuai dengan keinginannya atau yang dekat dengan lokasi dimana pengguna berada karena disertai dengan spesifikasi jarak terhadap lokasi yang dituju.

3. Aplikasi ini memberikan informasi mengenai rute yang ditetapkan untuk menuju lokasi yang dipilih.

4. Aplikasi ini berguna untuk meningkatkan pengembangan infromasi pelayanan kesehatan bagi masarakat yang membutuhkan.

\section{Saran}

Saran dari penelitian ini adalah :

1. Dalam pengembangan selanjutnya dapat dikembangkan lagi dengan mengoptimalkan keakuratan titik koordinat lokasi.

2. Pada pengembangan selanjutnya dapat menambahkan waktu tempuh dan mode penggunaan jalan kaki atau berkendaraan.

3. Masalah keamanan data, merupakan masalah yang sangat sering terjadi pada aplikasi - aplikasi yang dijalankan di internet. Oleh karenanya pihak administrator harus dapat meningkatkan keamanan aplikasi.

4. Diharapkan untuk penelitian selanjutnya dapat lebih memperluas cakupan pelayanan kesehatan tidak hanya disatu kota, namun dapat juga memberikan 
informasi dalam cakupan satu provinsi untuk memberikan akses yang terbaik bagi pengguna atau masyarakat.

6. Diharapkan didalam pengaplikasiannya, dapat ditambahkan marker atau gambar titik lokasi yang berbeda. Sehingga pengguna dapat membedakan dengan mudah yang mana apotek, klinik, puskesmas atau rumah sakit.

\section{Daftar Pustaka}

[1] Depkes. (2006). Keputusan Menteri Kesehatan Republik Indonesia Nomor 1027/MENKES/

[2] Mahdia, F., \& Noviyanto, F. (2013). Pemanfaatan Google Maps API Untuk Pembangunan Sistem Informasi Manajemen Bantuan Logistik Pasca Bencana Alam Berbasis Mobile Web. Jurnal Sarjana Teknik Informatika, e-ISSN :23, 3.

[3] Manongga, D., Papilaya, S., Pandie, S., Informasi, F. T., Kristen, U., Wacana, S., \& Salatiga, J. D. (2009). Sistem Informasi Geografis Untuk Perjalanan Wisata Di Kota Semarang. Jurnal Informatika, 10, 1-9. http://doi.org/10.9744/informatika.10.1.1-9

[4] Pramadya, J. S. A. (2011). Pembuatan Aplikasi Mobile Berbasis Android OS Untuk Mengetahui Lokasi Tempat Wisata di Daerah Istimewa Yogyakarta. Jurnal Skripsi STMIKAMIKOM YOGYAKARTA.

[5] Safaat, N. (2012). Pemograman Aplikasi Smartphone dan Tablet PC Berbasis Android. Bandung: Informatika.

[6] Komputer, W. (2013). Step by Step Menjadi Programmer Android. Semarag: Andy.

[7] Sugiarti, Y. (2013). Analisis \& Perancangan UML (Unified Modeling Language) Generated VB.6. Yogyakarta: Graha Ilmu.

[8] Tohari, H. (2014). ASTAH Analisis serta Perancangan Sistem Informasi melalui Pendekatan UML. Yogyakarta: Andy. 